\title{
COMPARATIVE STUDY OF REGULAR AND VERTICALLY IRREGULAR BUILDING UNDER SEISMIC LOADING
}

\author{
Ravi Kiran ${ }^{1}$, Sridhar. ${ }^{2}$ \\ ${ }^{I}$ M.Tech Student, Bengaluru, Structural Engineering, NCET, Karnataka, India \\ ${ }^{2}$ Sr.Associate Professor, Department of Civil Engineering, NCET, Karnataka, India
}

\begin{abstract}
It's a very big challenge that building or structure must withstand lateral forces such as earthquake and wind load. In the present work, the comparative analysis of various structures is performed using SAP 2000. The main aim of the project is comparative study of the stiffness of the structure by considering the three models that is Regular Structure, Plan irregular structure and Vertical irregular structure. All these three models are analyzed with static and dynamic earthquake loading for the Zones II, III, $I V \& V$. The results are tabulated and graphs are plotted for displacement, drift, base shear and time period. Based on the results and discussion the structural behavior and stiffness is concluded for regular and irregular structures, among these structures regular structure shown maximum displacement and drift for all the zones in both static and dynamic analysis.
\end{abstract}

Keywords: Tall structure, vertical Irregular, Lateral Displacement, Lateral Drift, Base Shear, Time period.

\section{INTRODUCTION}

Infrastructure construction includes owner, architect, structure engineer contractor \& some other local authority. They contribute for the good infrastructure and irregular building which is build in the seismic zone factor. The structural engineers need to have an understanding of the seismic response of the irregular structure. Lateral load imposed on the structure is the important factor in the study of tall building. Structural Engineer has been facing challenges to access the imposed drift requirements and minimizing the architectural strength of the structure as the building have got taller and taller. In response to this above concept, a large number of lateral resisting schemes are introduced for the tall buildings. In the recent days the tall structure has more importance especially in the metro Politian cities. The irregular building can't be avoided during the construction may due to space requirement in construction field so the tall structure has more demand .In the recent days the tall structure has more demand for the construction, the building must withstand against lateral force acting on the structure due to the natural calamities such as the earth quake and may also be wind load so in this project the comparative studies is done for the different zone by providing the required size of the columns and beams by following Indian standards If the design is not in a proper way means the sudden effect of earthquake may cause the structural collapse and life of people may spoil. So it may cause homeless to common people. So it is a major task to design structure in a proper way. The structure which performs against the earthquake means a structure must possess the simple, regular configuration and minimum lateral strength and also stiffness of the structure.

\subsection{Aim and Scopes}

1. The main objective of this project is to comparative study of the regular and vertically irregular building under earthquake forces.

2. Reinforced 20 storey's framed structure is considered in the study.

3. Both the regular RC building and irregular RC building is considered for this comparative study

4. To study the performance level of the structure.

5. In this project the comparative study of the various seismic parameters of different types of reinforced concrete moment reserving frames with types of irregular building.

6. Comparison to be done between regular, Plan irregular $\&$ vertical irregular frame on the basis of shear force

7. Bending moment, storey drifts, node displacement etc.

8. The reduction in drift, deflection and fundamental time period of the regular and irregular building studied.

9. The results of different parameters such as displacement, drift, base shear and time period to be studied

\subsection{Methodology}

The SAP 2000 software is good software, it is easy to understand to do the analysis and design of large complex building structure .It solves complex problem easily while comparing to the other available softwares. In this software the gridlines is established using Cartesian coordinate system and material which we taken is defined and place the membrane in the necessary grid line by using tool .Define the loads to the structure and assign the various types of the load to the structural members of the building. The mass sources, direction and mode shapes are the Dynamic properties can be defined.The output can be 
obtained after the analysis and tabulated and this output file can be extracted in other program. In this study the seismic behavior of the tall building with the effect of vertical irregularity plan vertical irregularity and regular building is examined by equivalent static method and response spectrum method. A comparative study is carried out in different cases of structures considered are

1. Regular building with different Zone that is $2^{\text {nd }}, 3^{\text {rd }}, 4^{\text {th }}$ and $5^{\text {th }}$.

2. Plan Irregular building with different Zone that is $2^{\text {nd }}, 3^{\text {rd }}$, $4^{\text {th }}$ and 5 th

3. Vertical Irregular building with different Zone that is $2^{\text {nd }}$, $3^{\text {rd, }} 4^{\text {th }}$ and $5^{\text {th }}$

\section{MODEL DESCRIPTION}

Structure

Number of stories

Type of Building -

$-20$

Irregular and plan irregular

Storey Height

Grade of Concrete

M30

Grade of steel

- Fe415

Beam Size

Column size

Slab size

Seismic Zone

Soil type

Importance Factor

Reduction Factor

Live Load

SDL

$-0.3 \times 0.6 \mathrm{~m}$

$-0.6 \times 0.6 \mathrm{~m}$

- $0.15 \mathrm{~m}$ thick

- II, III, IV and V

- II

$-1$

$-3$

$-3 \mathrm{KN} / \mathrm{m}^{2}$

$-2 \mathrm{KN} / \mathrm{m}^{2}$

All columns are assumed to be fixed at their base Regular building model is having symmetrical plan with plan dimension $40 \times 40 \mathrm{~m}$ where as the vertical irregularity building model and Plan irregularity model is having plan dimension of $40 \times 40 \mathrm{~m}$. The three dimensional model is carried out for the analysis. The columns and beams are of frame type elements whereas slabs and shear walls are of shell type element.

\section{RESULTS AND DISCUSION}

Results obtained by each models are discussed in this chapter. The analysis carried out by equivalent static and response spectrum method. The parameters discussed in this study include displacement, drift, base shear and time period. Parameters of different models of regular building are compared with the parameters of different models of plan irregular and vertical irregular building. In addition to this all models are evaluated with different types of zones are discussed.

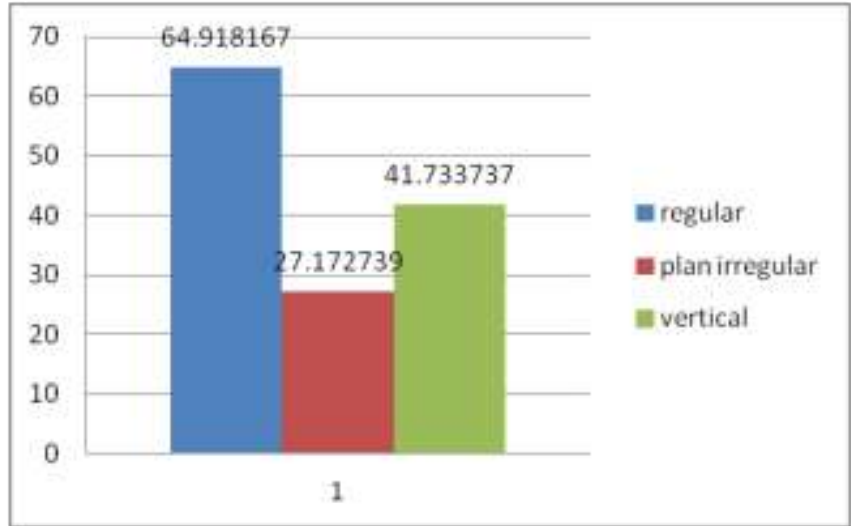

Chart -1 Graph showing Maximum Displacement of models for Zone 3 in Earth quake load in X Direction

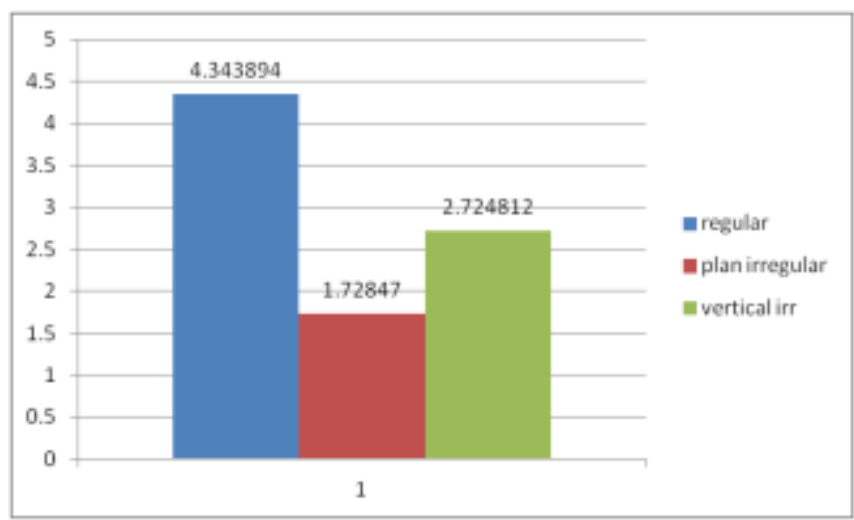

Chart -2 Graph showing Maximum Drift of models for Zone 3 in Earth quake load in X Direction

Figure shows the displacement of the structure in $\mathrm{X}$ direction/s number of the storey height for the structure with the Plan of irregularity ,Regular structure and vertical irregularity is subjected to seismic loading of Zone-3 From the graph, it is observed that the displacement of the structure with Regular structural building shows higher displacement compared to that of plan irregular and vertical structural building Maximum value for regular building is 64.918167,plan irregular building is 27.172739 and vertical building is 41.733737 and also the reduction percentage of plan irregular is $58.143 \%$ and vertical irregular building is $35.713 \%$ when compared with regular building

Figure shows the plot of maximum drift values in $\mathrm{X}$ direction for structures for seismic zone 3.The maximum drift of the Regular structure in was found to be 4.343894, 1.72847 for plan irregularity structural building and 2.724812 for the vertical irregularity of the structural building. 


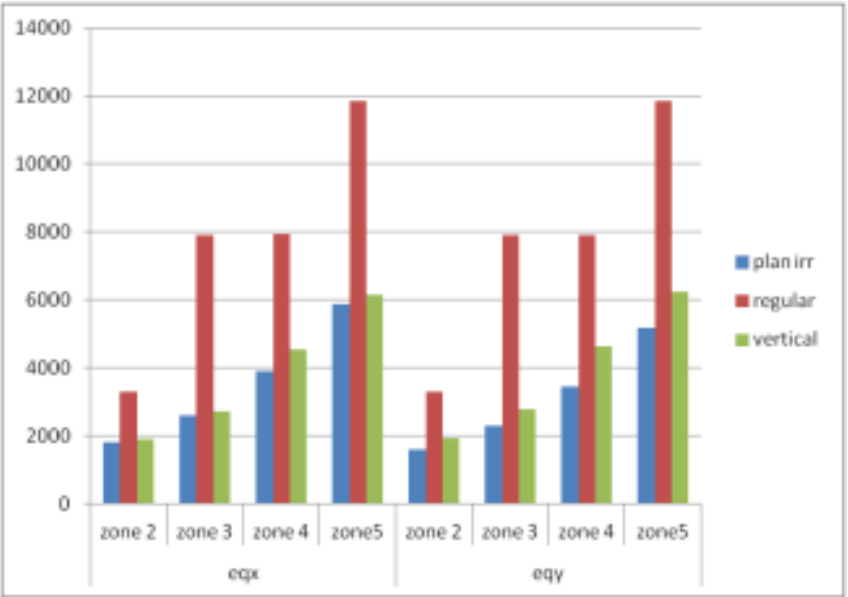

Chart -3: Base shear graph for zone II, III, IV, V OF Earthquake load in $\mathrm{X}$ and $\mathrm{Y}$ direction

Base shear graph of all the zone which is taken for the comparative study as zone I, zone II, zone III and ZONE IV for all the different structure as Plan irregularity, Regular structure and Vertical irregularity of the structure .In that shows graph shows Regular building shows the maximum value for base shear in each of the zone and plan irregularity of the building shows the less value or the least minimum value for the base shear graph

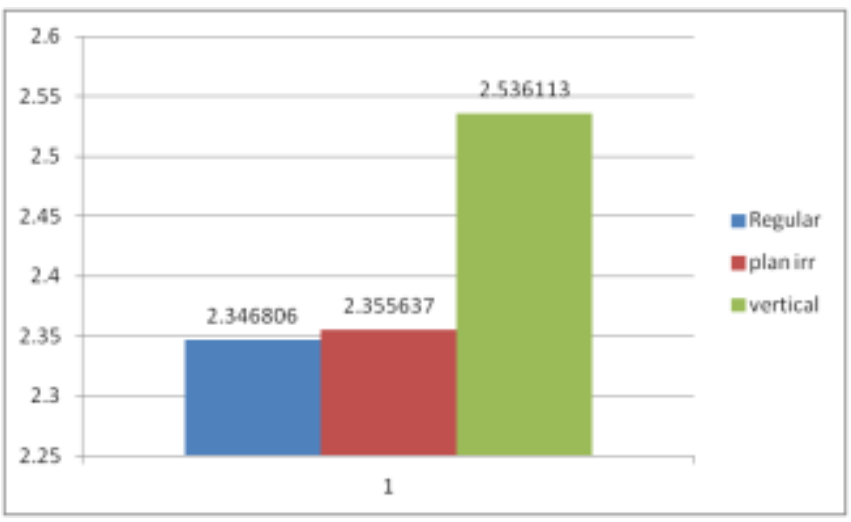

Chart -4: Time Period graph for Plan irregular, regular and vertical irregularity of the building

Time period graph for plan irregular, regular building and vertical irregularity of the structure .In the above graph tells that vertical irregular building shows maximum time 2.536113 seconds, regular structure shows minimum value time of 2.346806 seconds and plan irregularity of the building shows the time period of 2.355637 seconds as all of these values is shown in the above time period graph. The reduction percentage for Regular structure is $7.46 \%$ and for the Plan irregular structure as reduction factor 7.11

\section{CONCLUSION}

The analytic study is carried out in order to compare the behavior of regular structure with Plan and vertical irregularity. The structures are subjected to equivalent static and dynamic(Response Spectrum) seismic loading for the zone 2 , zone 3 , zone 4 and zone 5 From the study the following conclusions are obtained.
1. Among the three structures considered (Regular, plan irregularity and vertical irregularity), Regular structure shown maximum displacement and drift for all the zones in both static and dynamic analysis.

2. The fundamental time period for regular structure was found to be least and maximum for vertical irregular structure.

3. Base shear is maximum for Regular structure compared to other structures for all zones indicating regular structure is stiffer in static analysis.

4. Regular structure is stiffer compared to structures with plan and vertical irregularity.

5. Irregularity in the structure should be avoided however, sometimes due to architectural requirement or any other reasons irregularity needs to be provided. In such cases the structural arrangement should be such that deflection, drift and under permissible limits

6. Shear wall bracing may be provided in order to increase the stiffness of the irregular structure.

7. According to the time period graph the regular building as the minimum least point in the form of seconds so it conclude that the regular building is more strength against the lateral loads to the structure.

\section{SCOPE FOR FUTURE WORK}

1. The Scope of the study can be extended are below

2. Comparative study by providing shear wall at different location.

1. Comparative study by providing bracings and base isolation.

2. Non linear time history analysis can be performed on the structure.

\section{REFERENCES}

[1] Sagar R Pador, Rajashekar S Talikote study on "Review paper on service response of Multistoried building with mars irregularity" international journal of research in engineering \& technology,eISSN:23191163,pISSN:2321-7308, Issue: march 2015

[2] N Anvesh Dr.Shaik Yajdani, K Pavan kumar study on "Effect of mars irregularity on reinforced concrete structure using stabs" international journal of research in Engineering \& technology ,ISSN:23198753,ISSN:2347-6710,Issue:10 October 2015

[3] Ashish R Akhare, Abhijeet A Maske study on "Performance based seismic Design of RCC buildings with plan irregularity" Journal of Engineering \& technology ,ISSN:2349-8404,ISSN:2349879X, Volume 2,Issue: April - June 2015

[4] T.Sruti Sai Dr.T.Chandrashekar Rao, B.Vasudev study on "Seismic response of RC framed structure having plan and vertical irregularities with and without masonry infull action international research journal of Engineering \& technology,e-ISSN:2395-0056,pISSN:2395-0072,Volume:03, Issue: 02 Feb 2016

[5] Dileshwar rana, Prof Juned Raheem study on "Seismic analysis of regular and vertical geometric irregular framed building" international research journal of 
Engineering \& technology, Volume 43,pp.121-132, 04 July 2015.

[6] Mrs.Sagar B Patil, Prof Gururaj B Katti study on "Study of behavior of plan \& vertical irregularity by seismic analysis" international journal for scientific research \& development ,ISSN:2321-0613,Volume 3, Issue:04 2015

[7] Ashvin G Soni, Prof D.G Agarwal, D.A.M Pande study on "Effect of irregularities in building and their consequences international journal of modern trends in Engineering and research ,ISSN:23499745,ISSN:2393-8161,Issue: 2015

[8] Dr.S.K.Dubey, PD Sangannerkar study on "Seismic behavior of asymmetric RC building international

[9] journal of Advanced Engineering \& technology, EISSN 0976-3945,Volume 2,Issue: October - December 2011

[10] IS 1893-2002:Criteria for Earthquake Resistant Design of Structures

[11] IS 456-2000:Plain and Reinforced concrete.

[12] IS 875-1987:Code of Practice For Design Loads 